\title{
Repressive Hatred in a Politically Correct Discourse - A Philosophy of Education Perspective
}

\author{
Tammy Shel (Aboody) \\ Emek Yezreel College, Israel
}

\begin{abstract}
How to teach not to hate in a politically correct era? This is the topic of this paper. Israel's population comprises many cultures, religions, and ethnicities, in addition to gender complexity. In spring 2020 I taught undergraduates a course on multi-cultural identities through the lenses of caring. The students were required to read and/or watch The hate you give, by Angie Thomas, and to analyze 3 scenes of their choice, through critical race theory. I dedicated, in advance, several sessions on the dialectical and conflictual mixed identities that each individual and society possess. I aspired to establish a more genuine discourse on racism, sexism, and other forms of violence. After reading their papers, I was flabbergasted. Whether white or non-white students, most papers were consumed with toxic hatred toward white people. While I was contemplating my share, as the grader, I have been wondering how to discuss factors that induce racism, sexism, and the like in a less toxic manner; how to establish a trustworthy atmosphere in the classroom that encourages students to invoke biases and negative stereotypes, and to eventually grow from them? I suggest an ethnophilosophical pedagogy that galvanizes conflictual debates and can encourage both, teachers and students, to learn about each other and to unravel the influences and mechanisms that nurture racism, sexism, etc., and thereafter to heal the wounds. Such a pedagogy is motivated by a caring approach, and can thereby lead to a radical transformation that undermines oppressive forces that induce hatred and violence.
\end{abstract}

Keywords: caring, ethno-philosophy, politically-correct, sexism-racism, education 